\title{
Public and private collaboration in establishing a young person's sexual health clinic in a commercial setting
}

C M Mackie, MFFP, SCMO, Family Planning and Reproductive Health Care, The Sandyford Initiative, Glasgow, UK; L Elliot, MSc, Senior Health Promotion Officer, Greater Glasgow Health Board, Glasgow, UK; D A M Thomson, BSc Pharm, MR Pharm, Primary Care Services Manager, Boots the Chemist, Glasgow, UK; A Bigrigg, MRCOG, MFFP, Clinical Director, The Sandyford Initiative, Glasgow, UK; K F McAllister, MRCOG, DFFP, Consultant in Family Planning and Reproductive Health Care, The Sandyford Initiative, Glasgow, UK

Correspondence: Dr K F McAllister, The Sandyford Initiative, 6 Sandyford Place, Sauchiehall Street, Glasgow G3 7NB, UK. Tel: +44 (0) 141211 8130.Fax: +44 (0) 141211 8139.E-mail: Kay.McAllister@glacomenscot.nhs.uk

(Accepted $5^{\text {th }}$ July 2002)

The Journal of Family Planning and Reproductive Health Care 2002: 28(4): 201-203

\begin{abstract}
Objective. To define the key factors and constraints in public-private sector collaboration in establishing and delivering a young person's sexual health clinic within an existing commercial establishment.

Consultation, planning and implementation phases. Consultations were held between the Health Promotion Department, family planning and commercial outlets, resulting in the establishment of the UK's first sexual health service within commercial premises. Once the clinic had been operational for 6 months, a single researcher carried out semi-structured interviews with 13 staff representing all levels within the partner organisations.

Post-implementation interviews. There was agreement by all interviewees on the objectives of the clinic. The problems encountered during the establishment of the service were with the legislation pertaining to pharmacies and the adverse press coverage of a minority public view of the provision of sexual health services to young people. No respondent identified conflict between the aims of the clinic and the strategic objectives of their organisation.

Recommendations. Common aims are imperative for successful interagency working. Wider initial consultations may have helped to identify potential problems and confirm common aims at an earlier stage of the development of the project. The involvement of senior management may also have improved the smooth running of the project.
\end{abstract}

\footnotetext{
Key message points

- Partnerships between commercial and statutory bodies are possible, but involve extensive negotiations.

- The functioning of commercial bodies differs significantly from that of the National Health Service (NHS).

- Innovative approaches require alternative strategies to overcome problems between different organisations.
}

\section{Introduction}

Glasgow's family planning service has recognised the need to try innovative ways of providing sexual health services for young people, particularly as the teenage pregnancy rate remains high. ${ }^{1-3}$ The government's white paper, Towards a healthier Scotland, identified the need for partnership working in an effort to tackle this problem. ${ }^{4,5}$ It was felt that access to services could be improved if a service was sited in a city centre non-medical setting. Within Glasgow, the Family Planning and Sexual Health Directorate of the Primary Care Trust have well-established links with the sexual health team of the Health Promotion Department of the Health Board. Both groups recognised the need to develop further links with commercial organisations locally with a view to utilising their premises for the delivery of clinical services.

\section{Consultation, planning and implementation phase}

The consultation, planning and implementation phase lasted from the inception of the idea in March 1998 until the service opened in December 1998. Initial talks were held with a leading pharmacy outlet and a national multimedia retailer. Both are settings accessed regularly by young people. Although sexual health services have been established in schools, ${ }^{6}$ this concept of public and private collaboration was new, and we were unable to look to the experience of others for guidance. The aim was to provide a sexual health service for young people with onsite contraceptive advice and provision. The staff and supplies would be provided and funded by the Primary Care Trust, as with all other outreach work, whilst the accommodation was to be provided and funded by the commercial organisation. As expected, some difficulties arose as a result of differing priorities between public and private bodies. At a local level, personal views prevented this venture being established at the multimedia retailer, despite initial interest expressed by their national management. A partnership was eventually agreed with a pharmaceutical retailer. This resulted in legislative difficulties that were unfortunately not recognised early in the planning phase. Agreement had to be obtained from the Area Pharmaceutical Committee, the local advisory committee on pharmacy matters, prior to the commencement of the service. All local pharmacists are contracted by the Health Board and, therefore, have a statutory right to be consulted and approve changes that affect pharmacy services. ${ }^{7}$ Within pharmacy premises the dispensing of medication requires the supervision of a pharmacist. ${ }^{8}$ An application was therefore made to the Pharmaceutical Society, which licences both pharmacists and pharmacies, to deregulate an office for the use of this service. The aim was for client consultations with a family planning doctor to take place within this deregulated room. An information point, providing health literature aimed at young people and information on the service, was to be sited elsewhere within the store. The staffing of this point was to be shared between a family planning nurse and a health promotion sessional worker. An initial advertising campaign was organised by the Health Promotion Department, comprising stickers for toilet doors in bars, nightclubs and cinemas throughout the city centre. The full advertising budget was spent on this campaign as it was expected that ongoing advertising would be via a 
prominently placed in-store information point and peer recommendation. ${ }^{9,10}$

The serviced launched in December 1998 with a twiceweekly 2-hour session. The partners were unprepared for the degree of condemnation from national newspapers reflecting a minority public view. ${ }^{11-14}$ Organised demonstrations followed, which may have influenced the service attendance. The resulting disquiet led to the information point, which was planned as a focus for the service, being placed in a non-prominent position within the store alongside the public pharmacy counter. The retailer, however, thought that this was the most appropriate site for the stand as the service was 'health-related'.

\section{Post-implementation interviews: method}

An independent researcher was commissioned to conduct semi-structured interviews with members of staff representing all levels throughout the partner organisations. The aim was to ascertain their views in relation to the objectives and planning of the service, the facilities available and whether they felt that the service was compatible with their organisation's long-terms strategies. Once the service had been operational for 6 months, 13 interviews were conducted. Five interviewees represented Greater Glasgow Health Board, four represented family planning and four represented the pharmaceutical retailer. Ten interviews were carried out in person and three by telephone. The same researcher conducted all the interviews.

\section{Post-implementation interviews: results}

The 13 interview results are presented by theme with the major points identified but not attributed to individuals as a promise of confidentiality was made to all respondents.

\section{Objectives of the clinic}

All respondents confirmed the broad aims for the service that had been agreed during the consultation process. These were to provide a source of sexual health and contraceptive advice for young people and to reach out to young people who might not otherwise seek advice for help on this topic. The overall public health aim of both these objectives was to reduce the pregnancy rate and several respondents highlighted this.

\section{The planning phase}

Initial enquiries with various commercial outlets resulted in formal discussion between the eventual three partners from April 1998 onwards. Although all respondents felt that the planning phase had been effectively managed, they also identified the same main constraints. Apart from the legal issues, there was a failure to consult fully with the pharmaceutical adviser from the Health Board or the Area Pharmaceutical Committee. This resulted in disquiet amongst local pharmacist's representatives who felt that they should have been given the opportunity to participate in this venture. The other consultation failure was with nonpharmaceutical staff within the commercial outlet that impinged on practical matters such as storage space for leaflets.

\section{Publicity}

Every respondent felt that the publicity materials were well designed and appropriate. The distribution of materials in pubs and clubs was though by some to be inappropriate to reach the younger clients of the target group. It was universally agreed that the most effective publicity for the clinic, initially, had been the unexpected and unwelcome press campaign. During the planning phase, none of the partners had anticipated the possible extent of the adverse press coverage and demonstrations by opposition groups. All those interviewed stated that this had been a difficult time but felt that it was overcome by a sensible united approach. Despite this very difficult situation it was felt by all the partners that this adverse publicity was in actual fact a positive help to the clinic (no more funding was available for our own advertising at that point).

\section{Location and opening times}

A city centre retail location was felt by all to be ideal for attracting young people. It was easy to reach by public transport and offered anonymity. The opening times were felt to be appropriate. Other times, such as Saturdays, were also identified as good alternatives. However, given the constraints of the availability of the office space used, the times chosen were considered by those interviewed to be the best compromise.

\section{Operational aspects}

All respondents agreed that there were drawbacks in using a location outside health service premises. These were the need to transport drugs to and from the location for each session and the unavailability of client records on site. The original plan, using a laptop linked to the family planning database, would have avoided this problem. Unfortunately there was no direct outside telephone line for this facility. The waiting area, on the shop floor, could get busy at times and respondents identified lack of privacy as a problem.

\section{Impact on the service on retail staff}

The service did not alter the workload of shop floor staff. There was a welcomed increase in enquiries to pharmacy staff. These enquiries were spread throughout the week and not confined to service times.

\section{Strategic issues}

Interviews were concluded by asking partners how they saw the service fitting in with the strategic aims of their organisation and to anticipate any areas of conflict. No interviewee identified any overt conflicts of aims. One of the long-term strategic objectives of this retail pharmacy outlet is to expand the role of the pharmacist. They hope that introducing health-related activities within their premises might facilitate this. The health service respondents felt that their main strategic intentions of providing good sexual health services to young people was being addressed by this service.

\section{Reflection}

The government paper, Towards a healthier Scotland, has highlighted the need to reduce the number of teenage pregnancies. ${ }^{4}$ Pharmacists as a profession have a major role to play in advising the public on health issues, and as such are ideal partners in initiatives that impact on public health. Alternative retailers were approached in the planning phase. On reflection, the eventual partnership with a pharmaceutical organisation was a natural place to site health care provision, fitting in well with the pharmacist's professional role. There was also the advantage that they could answer many queries outside the service opening times. This would have been impossible in any other retail setting.

Despite the difficulties of a joint venture between public and private sectors, this innovative project increases accessibility to sexual health services for young people. 
Wider consultation at an earlier stage of the project's development, perhaps with senior management and marketing departments, might have prevented many of the problems encountered such as the non-recognition of the legal issues surrounding use of pharmacy premises and the adverse publicity attendant on the launch of the service. This adverse publicity may have led to the retailer withdrawing from the partnership but thankfully overall had no impact on sales within the store. On reflection, this publicity led to an increased public awareness of the service and we therefore had no need to try and obtain more funding for further publicity.

The failure to consult more widely in the initial planning phase could have had serious legal consequences. The service would have been operating outside the law had the need to deregulate a room not been recognised in time.

The start of the service could have been delayed had the Pharmaceutical Society not reacted promptly to the pharmacist's request for deregulation. An alternative would have been to issue prescriptions to clients in place of medication, adding significantly to the costs of the service. In future, if such initiatives are planned, consideration must be given to their impact on other agencies and the contribution that these agencies could impart to the success of them. In this instance the partners only considered their own organisations, without thinking through the implications of using pharmacy premises. In anticipation of public interest in such an innovative service, a press launch was arranged immediately prior to its commencement to which all major news agencies were invited. No one attended the press launch, although two Scottish daily newspapers published the issued press release on the day of the launch. The storm of adverse publicity and press furore that subsequently ensued had not been anticipated by any of the partners. The staff involved was put under significant strain. In future any similar service should plan for such an eventuality by ensuring that senior management and marketing departments take a proactive approach. More involvement and discussion with national media through the appropriate organisational departments might have mitigated the publicity that surrounded the launch of this initiative. A common approach to press and interested members of the public was negotiated between the partners in response to this.

All those who took part in the interviews identified the same common aims for the clinic that are vital for any interagency initiative to function successfully. The informality of the partnership arrangements has worked well in this instance, with no formal contact between partner organisations. This may reflect the degree of agreement between the partner organisations about the project aims. More formal arrangements may be required in other partnerships settings; however, in the absence of any other similar projects we are only able to offer our own experience as guidance in this area.

Statements on funding and competing interests

Funding. None identified.

Competing interests. None identified.

References

1 The Scottish Needs Assessment Programme. Teenage pregnancy in Scotland. Glasgow: Scottish Forum for Public Health Medicine, 1994. 2 Information and Statistics Division (ISD) of the Common Services Agency for the Scottish Health Service. Teenage pregnancy in Scotland, 1989-1998. Health Briefing, 99/04: 1-8, 1999.

3 Morrison A, Mackie CM, Elliot L, et al. The Sexual Health Help Centre: a service for young people. J Pub Health Med 1997; 19: $457-463$.

4 The Scottish Office. Towards a healthier Scotland. Edinburgh: The Stationary Office, 1999

5 Bloxham S. The contribution of interagency collaboration to the promotion of young people's sexual health. Health Educ Res 1997; 12: 91-101.

6 Peak GL, McKinney DL. Reproductive and sexual health at the school based/school-linked health centre: an analysis of services provided by 180 clinics. J Adolesc Health 1996; 19: 276-281.

7 The National Health Service (NHS) (Scotland) Act 1978, Section 9, as amended by the National Health Service and Community Care Act 1990.

8 The National Health Service (NHS) (Pharmaceutical Services) (Scotland) Regulations 1995 Schedule 1(5).

9 Shucksmith J. Hendry LB. Young people's perceptions of their own health needs: a report of a project funded for the Health Education Board for Scotland. Edinburgh: Health Education Board for Scotland, 1996.

10 Milburn K. Peer education, young people and sexual health: a critical review. Edinburgh: Health Education Board for Scotland, 1996.

11 Press release. The Daily Mail, Tuesday 1st December 1998; 1.

12 Press release. The Daily Mail, Friday 5th December 1998; 17

13 Press release. The Evening Times, Monday 30th November 1998; 14

14 Press release. The Evening Times, Thursday 28th October 1999; 1.

\section{Evaluation of a young person's sexual health service in a commercial setting}

K F McAllister, MRCOG, DFFP, Consultant in Family Planning and Reproductive Health Care, The Sandyford Initiative, Glasgow, UK; L Elliott, MSc, Senior Health Promotion Officer, Greater Glasgow Health Board, Glasgow, UK; D A M Thomson, BSc Pharm, MR Pharm, Primary Care Services Manager, Boots the Chemist, Glasgow, UK; A Bigrigg, MRCOG, MFFP, Clinical Director, The Sandyford Initiative, Glasgow, UK; C M Mackie, MFF, SCMO, Family Planning and Reproductive Health Care, The Sandyford Initiative, Glasgow, UK

Correspondence: Dr K F McAllister, The Sandyford Initiative, 6 Sandyford Place, Sauchiehall Street, Glasgow G3 7NB, UK. Tel: +44 (0) 141211 8130.Fax: +44 (0) 141211 8139.E-mail: Kay.McAllister@glacomenscot.nhs.uk

(Accepted $5^{\text {th }}$ July 2002)

The Journal of Family Planning and Reproductive Health Care 2002: 28(4): 203-205

\section{Abstract}

Objective. To determine the acceptability and accessibility of a sexual health service for young people in a city centre pharmacy.
Design. Prospective qualitative survey of clients attending a new sexual health service, including client characteristics and semi-structured interviews.

Participants. Clients attending the service between January and May 1999. 